\title{
«Caritas in veritate»: la «kehre» de la Doctrina Social
}

\author{
BERNARDO PÉREZ ANDREO \\ Instituto Teológico de Murcia (España) \\ b.perezandreo@gmail.com
}

\begin{abstract}
Resumen
La encíclica Caritas in veritate ha supuesto una verdadera «kehre» en la doctrina social de la Iglesia. El giro viene dado por el cambio operado en la evaluación del capitalismo, término que no aparece en todo el texto y que por ello mismo ha sido «forcluido». Esta «forclusión» del capitalismo supone su tácita aceptación como modelo natural de relación económica entre los hombres según la Iglesia. Esto no había sido aceptado nunca por la Iglesia, cuyo discurso siempre fue de aceptación crítica, pero nunca de aceptación tácita. Se hace necesario volver al cauce de la doctrina que marcaron el Concilio Vaticano II, Pablo VI y Juan Pablo II.
\end{abstract}

Palabras clave: capitalismo, civilización del amor, forclusión, kehre.

\section{«Caritas in veritate»: the «kehre» of Social Doctrine}

\begin{abstract}
The encyclical Caritas in veritate it made a real "kehre» in the Church's social doctrine. The turn is caused by the change in the consideration of capitalism, a term that has not exactly like the text and which therefore has been «foreclosed》. This «forclusion» is the tacit acceptance of capitalism as a natural model of economic relations among men. This had never been accepted by the Church. It is necessary to return to the doctrine that marked the Second Vatican Council and followed by Paul VI and John Paul II.
\end{abstract}

Key words: capitalism, civilization of Love, forclusion, kehre.

Doctor en Teología por la Facultad de Teología «San Vicente Ferren» de Valencia. DEA en Filosofía por la Universidad de Murcia. Profesor Titular de Teología en el Instituto Teológico de Murcia OFM. Acaba de publicar La verdadera religión. El intento de Hume de naturalizar la fe (2009); y de inminente publicación Descodificando a Jesús de Nazaret. El mundo antiguo y las primeras comunidades cristianas. Ediciones Irreverentes, Madrid 2010. 


\section{Introducción}

No son muchas las ocasiones de las que dispone un teólogo de ponerse delante de un texto del Magisterio al más alto nivel y se encuentre con un sustancial problema de forclusión de la realidad ${ }^{1}$. En el caso que nos ocupa hay un término que no aparece ni una sola vez en todo el documento, es el término que desde 1991 había desaparecido del Magisterio oficial de la Iglesia sobre la cuestión social para referirse al modo de organización al que el mundo ha sido sometido desde hace dos siglos, pero especialmente en los últimos dos decenios: el capitalismo. Efectivamente, fue Juan Pablo II el que hiciera una severa advertencia en el número 35 de Centessimus annus, cuando afirmara la imposibilidad de aferrarse al capitalismo una vez caído el socialismo. Es más, allí nos da la clave de la caída de aquello que se vivía tras el telón de acero: no era un socialismo verdadero sino un capitalismo de Estado, donde el Estado actúa como único capitalista que amasa la fuerza de trabajo de todos los seres humanos que están bajo su égida.

Benedicto XVI no tiene un discurso sobre el capitalismo y sus referencias son meramente tangenciales, incluso algunas realizan una lectura sesgada del texto de Juan Pablo II que hemos citado arriba cuando dice sobre aquél: «en la encíclica Centesimus annus escribió Juan Pablo II "la moderna economía de empresa comporta aspectos positivos, cuya raíz es la libertad de la persona, que se expresa en el campo económico y en otros campos' (n. 32). Sin embargo —añadió-, no se ha de considerar el capitalismo como el único modelo válido de organización económica'»². Decir esto es no haber asimilado la crítica que allí se hace al sistema, más bien se tuerce el sentido diáfano de una

1 El término «forclusión» lo tomamos en el sentido que Lacan le dio en el Seminario III. Se trata de un proceso psicótico por el que un determinado significante, habitualmente el Nombre del Padre, queda eliminado del orden representacional y simbólico del sujeto. A partir de ese momento, el significante forcluido es sustituido por otros que vienen a compensar el vacío, pero que suponen la base de la psicosis. La forclusión proviene de una mala interiorización del principio de realidad. Por otra parte, el término, proveniente del idioma galo, es propio del ámbito jurídico, en el que designa un principio de la legislación procesal por el cual los derechos que se reclaman, de hacerse fuera de plazo, caducan, es decir, quedan forcluidos. En el ámbito de lenguaje jurídico español existe el término «preclusión», pero el término francés tiene más extensión de uso. En este trabajo utilizamos tanto el significado jurídico del término como el psicoanalítico. Entendemos que ambos pueden generar un valor teológico para el término.

2 Benedicto XVI: Angelus, Palacio apostólico de Castel Gandolfo, Domingo 23 de Septiembre 2007. 
denuncia del capitalismo como sistema que pretende ser el modelo a adoptar por todos tras el fracaso del socialismo.

La encíclica da la sensación en todo momento de no estar ajustada a la realidad que se vive en los últimos tiempos. Su publicación debía coincidir con el aniversario de la Populorum progressio, pero los acontecimientos del año 2007 hicieron prudente su postergación a la espera de medir el calado de los mismos. Esa medida parece que se realizó con la misma vara con la que han medido los organismos internacionales y por ello la encíclica se desliza por la misma pendiente que aquellos: miopía económica y presbicia moral. Miopía económica porque los grandes organismos que fueron incapaces de ver a lo lejos (característica del miope) la crisis que se avecinaba, diagnosticaron un mal meramente financiero que se solucionaría con multimillonarias inyecciones de dinero público, como la encíclica parece entrever; presbicia moral porque no se alcanza a ver, por cansancio y vejez (presbysanciano), que lo que está en juego es el núcleo mismo del modelo económico, social y político en el que vivimos, eso que todos los que mantienen intacta la visión llaman capitalismo y que no ha dejado de conducir a la humanidad entera hacia un abismo de difícil solución, donde no sólo la naturaleza, sino el ser humano mismo, está siendo engullido por un modelo económico que tiene su leitmotiv en el crecimiento constante y desaforado de los beneficios.

Se hace necesario recordar que Santo Tomás prevenía con dureza contra una de las realidades que hoy están a la base del sistema financiero capitalista: la usura. En la famosa cuestión 78 de la Secunda Secundae explica con absoluta claridad que cobrar una cosa y su uso, de ahí usura, es ilícito y pecado, por tanto debe ser devuelto. Cuando en el mundo de las finanzas se invierte dinero para obtener dinero, se está haciendo algo ilícito y pecaminoso en sí mismo. Como bien dice el Aquinate, el que presta algo tiene derecho a que se le devuelva lo prestado, pero si alguien presta dinero y se le devuelve la suma prestada, los intereses que se exigen suponen el cobro de lo que no existe o bien el cobro por el uso, de modo que se habría cobrado dos veces lo mismo: una la cantidad prestada y otra vez el uso de esa cantidad, por ello es usura, ilícita y un pecado grave porque se asocia a la avaricia: deseo inmoderado de poseer riquezas (ver la cuestión 118$)^{3}$.

También Summa Theologica II, II, q. 78: «Recibir interés por un préstamo monetario es injusto en sí mismo, porque implica la venta de lo que no existe, con lo que manifiestamente se produce una desigualdad que es contraria a la justicia. Para su evidencia, debe recordarse que hay ciertos objetos cuyo uso consiste en su propia consumición; así consumimos el vino utilizándolo para la bebida y el trigo al emplearlo para la comida. De ahí que en estos casos no deban computarse separadamente el uso 
En la línea trazada por Deus caritas est y Spe salvi, Caritas in veritate pretendía apuntalar el tercero de los pilares del cristianismo: la caridad. Pero adolece de una perspectiva oblicua en la legitimación bíblica, es decir, no va a los textos que todos los especialistas consideran los clave para hacer una reflexión sobre el tema propuesto. En Deus caritas est había una clamorosa ausencia en la fundamentación del amor de Dios: Mt 25, 31ss, apenas una cita marginal en el texto; en Spe salvi, Ap 20-21; y en la actual encíclica, el Sermón del Monte en Mateo, con los ayes subsiguientes, y el sermón del Llano de Lucas. Las tres ausencias no son casuales, obedecen a un modo de entender tanto la teología como el mundo: una visión neoagustinista. Con este término queremos resumir las posiciones que refleja la encíclica, a saber: naturalismo económico, sobrenaturalismo político y eclesiocentrismo. Con esta terminología hacemos referencia a las tres claves que se nos antoja permiten comprender cómo se ha llegado a este acto fallido ${ }^{4}$. Por naturalismo económico entendemos que la encíclica acepta la economía capitalista como el modelo económico que nos viene dado por la naturaleza misma de las cosas; también, llamamos sobrenaturalismo político a lo que tradicionalmente se ha denominado como agustinismo político: existe un orden cósmico que incluye dos autoridades, una política y otra eclesiástica, sometida aquella a esta. Es voluntad expresa de Dios que la Iglesia sea el cauce natural por el que los hombres construyen un mundo verdaderamente humano, no habría humanidad más allá de los límites del cristianismo tipificado en la Iglesia católica. A esta última proposición la hemos llamado eclesiocentrismo: la Iglesia católica es el centro de todo lo verdaderamente humano en el mundo. Fuera de la Iglesia católica, fuera de sus estructuras morales y de sus juicios políticos, no habría salvación alguna para la humanidad. Todos los males que se abaten sobre el mundo de hoy vendrían derivados del abandono de la fe y de la escasa presencia de la Iglesia en el mundo, no se deberían a que el sistema económico sea perverso en esencia, en todo caso se han pervertido los que hacen uso del sistema.

de la cosa y la cosa misma, sino que a todo aquel a quien se concede el uso se le concede también la cosa misma. De ahí que, tratándose de tales objetos, el préstamo transfiere la propiedad de los mismos. Luego si alguien quisiera vender de una parte el vino y de otra el uso del vino, vendería dos veces la misma cosa o vendería lo que no existe; y por esta razón cometería manifiestamente un pecado de injusticia. Por igual motivo comete una injusticia el que presta vino o trigo y exige dos pagos: uno, la restitución del equivalente de la cosa, y otro, el precio de su uso, de donde el nombre de usura».

4 Entendemos por acto fallido, aquel acto que manifiesta la intención no manifiesta del autor mediante la patentización del fallo. 
En lo que sigue haremos una breve disección de este neoagustinismo que presenta la encíclica y lo haremos en dos epígrafes. En el primero mostraremos algunas causas y consecuencias de esta doctrina que se reflejan en el título extraído de la propia encíclica en el número 7: hacia la ciudad de Dios universal a la que avanza la bistoria humana. Para el segundo apartado dejamos lo que podría ser considerado como el mayor olvido de la encíclica, olvido que supone el no tematizar el tema más prometedor de la doctrina de la Iglesia sobre la cosa social: la Civilización del amor que iniciara Pablo VI y no olvidara Juan Pablo II. Esta civilización del amor debe tener su extensión en la Civilización de la pobreza que auspiciara Ellacuría y continuara Sobrino, como nosotros mismos hemos escrito en otro lugar 5 . Estos dos epígrafes tienen su razón de ser en la explanación de lo que hemos denominado la forclusión del capitalismo, pero eso queda para el epílogo.

Nos proponemos lanzar algunas pistas para el debate crítico entre hermanos en la fe que pretenden, como el mismo Jesús, la construcción del Reino de Dios en la tierra, especialmente en un mundo en quiebra y necesitado de propuestas audaces. Pedimos a los lectores que apliquen la caridad hermenéutica imprescindible para llegar al conocimiento de la verdad que el autor ha perseguido en el texto. De cumplirse esta caridad en la verdad que ha movido al autor, aumentará el conocimiento de la fe y la práctica de la justicia.

\section{Hacia la ciudad de Dios universal}

La introducción y la conclusión de la encíclica, números del 1 al 9 y 78-79, son el resumen y lo más actual de la misma, de hecho hay quien afirma que en esos párrafos se nota la mano del actual pontífice, el resto es una aplicación de lo dicho en la introducción, de ahí que bastaría una explicación línea a línea para abordar la encíclica. Como algún comentarista ha dicho, la encíclica es demasiado larga y el motivo es que tiene una intención primera que se vio desplazada por la crisis financiera del año 2007, justo cuando se tenía previsto publicar el texto, texto que venía anunciándose desde un año atrás. Querer hacer coincidir la encíclica con el aniversario, el cuarenta, de la Populorum progressio de Pablo VI, efemérides que sólo había merecido la primera de la saga de encíclicas sociales, dio la oportunidad al redactor de remodelar por completo un texto que los hechos periclitaban rápidamente. Cualquiera

B. PÉREZ ANDreO: “¿Iglesia vs. Globalización? Hacia la civilización del amor”, Veritas 18 (Marzo 2008) 181-208. 
que hubiera estado atento a la realidad hubiera analizado los acontecimientos como la crisis del capitalismo, no como una crisis más en el capitalismo. Pero no fue así y el redactor se convenció de que lo esencial de la encíclica debía permanecer, añadiendo algún capítulo o algunos números en los capítulos preexistentes, de ahí lo excesiva que se antoja su extensión.

Una vista somera de los capítulos nos permite ver que la encíclica forma parte del pasado. Primero porque pretende hacer valer para la sociedad actual el análisis de hace cuarenta años, cuando el capitalismo vivía sus treinta gloriosos y los males verdaderamente importantes del mismo estaban tapados por la lucha de bloques. De hecho, esta encíclica tendría un valor como análisis del pasado, más no como análisis del presente, menos del porvenir. Para analizar el capitalismo industrial de los años sesenta hasta los noventa, no era necesario recuperar los análisis de Populorum progressio, eran mejores los que Juan Pablo II realizó tanto en Solicitudo rei socialis como en la magnífica Centesimus annus. En ambas obras quedaba a la luz la inhumanidad de un modelo económico que tiene su motor esencial en el enriquecimiento constante y en la conversión de valor social en valor privado. Por tener esta maldad intrínseca se hizo necesario recurrir a un término que aplicara las responsabilidades del modelo, no bastaba con las responsabilidades morales individuales para generar el mayor crimen histórico contra el hombre y el planeta. La expresión estructuras de pecado bien podría resumir lo que supone el capitalismo en cuanto régimen económico, social y político que se autogenera a partir de los egoísmos particulares de los integrantes del mismo. Por eso entendemos que esta encíclica supone una regresión a concepciones individualistas de la economía que no hacen sino legitimar el orden existente ${ }^{6}$, no de otra manera puede comprenderse el siguiente párrafo de la misma tomado del número 65:

Además, se requiere que las finanzas mismas, que han de renovar necesariamente sus estructuras y modos de funcionamiento tras su mala utilización, que ha dañado la economía real, vuelvan a ser un instrumento encaminado a producir mejor riqueza y desarrollo. Toda la economía y todas las finanzas, y no sólo algunos de sus sectores, en cuanto instrumentos, deben ser utilizados de manera ética para crear las condiciones adecuadas para el desarrollo del hombre y de los pueblos. [...]

\footnotetext{
6 Dice González-Carvajal que la supuesta regresión a posiciones preconciliares se debe al carácter deductivo de su argumentación, carácter que tras el Concilio fue abandonado por una metodología inductiva en el análisis de las realidades sociales: L. GONZÁLEZ-CARVAJAL SANTABÁRBARA: "Claves para entender la encíclica Caritas in veritate", Conrintios XIII, 132 (2009) 16.
} 
Sobre todo, es preciso que el intento de hacer el bien no se contraponga al de la capacidad efectiva de producir bienes. Los agentes financieros han de redescubrir el fundamento ético de su actividad para no abusar de aquellos instrumentos sofisticados con los que se podría traicionar a los ahorradores. Recta intención, transparencia y búsqueda de los buenos resultados son compatibles y nunca se deben separar.

Hemos destacado con cursiva los términos que creemos son los goznes del pensamiento del autor. Para éste, no hay crisis del capitalismo, se trata de una simple crisis financiera que ha afectado al sector productivo, de no haberlo hecho se podría decir que los agentes financieros tenían derecho a seguir tal como estaban haciendo, pero como esto ha supuesto un impedimento a un bien superior como es la producción de bienes, entonces se hace necesario que vuelvan a ser un instrumento para la generación de riqueza, como si alguna vez lo hubieran sido. Los instrumentos financieros tan sofisticados que hoy se utilizan apenas tienen nada que ver con la producción de riqueza para todos. Son meras estructuras de enriquecimiento ilegítimo en manos de aquellos que se han hecho con el poder económico. Mediante la ingeniería financiera se consigue dominar los mercados mundiales y por tanto generar dinero por medio de dinero, sin ningún tipo de relación con la mercancía o los productos. No existen trabas de ningún tipo para el monopolio del dinero financiero que genera riqueza para unos pocos a costa del $95 \%$ de la humanidad. No hay nada a lo que volver, puesto que siempre fue, es y será un sistema de robo global de la riqueza.

Acto seguido de hacer una admonición a la vuelta a una inexistente ética de las finanzas -ética que de existir sólo lo sería en los manuales de las facultades de economía, ni siquiera en las clases pues nadie se lo toma en serio; el capitalismo es un sistema de enriquecimiento rápido y sin escrúpulos que no conoce más ética que la calvinista - se recuerda que sobre todo, es decir, por encima de cualquier otra consideración, la ética no puede ser un obstáculo para el fin de la economía: la producción de bienes. El problema fundamental no es sólo lo que el texto dice, sino también lo que presupone. De un lado afirma la necesidad de hacer el bien sin impedir la creación de bienes, del otro presupone que los bienes son los beneficios de las empresas y el bien es un acto meramente caritativo, como esa caridad que en la introducción criticaba como sensiblería barata. Hacer el bien, sobre todo, no puede ser un obstáculo para ganar dinero.

Después de esto, vuelve a insistir en la privatización de las responsabilidades. Los agentes financieros deben redescubrir el fundamento ético de su actividad. No se trata de que las finanzas sean 
inmorales, sino de que los agentes de las mismas han perdido lo que otrora guiara su actuación: el fundamento ético, su responsabilidad personal por los demás, el mirar siempre a la vez por el bien de los otros en su gestión. A la privatización de la responsabilidad le sigue la ingenuidad analítica de la actividad financiera: los brokers son tiburones en el parqué, son buitres a la búsqueda de carroña, son chacales que esperan la debilidad para acabar con su presa ${ }^{7}$. No se hace necesario justificar esto, pues lo hemos visto con meridiana claridad. Quien no vea lo que afirmamos lo hace desde una ingenuidad injustificable o desde una perspectiva legitimadora, de ahí que la expresión final de la cita: recta intención, transparencia y búsqueda de los buenos resultados son compatibles y nunca se deben separar, posee un mera intención ideológica: justificar la existencia de una compatibilidad entre el beneficio financiero y la actitud moral, compatibilidad que la realidad desmiente cabalmente.

Quizás está pensando el autor en la responsabilidad social corporativa, tan de moda en los programas formativos de los centros de estudio, cuando en el número 45 dice que la economía necesita de la ética, y añade: «hoy se habla mucho de ética en el campo económico, bancario y empresarial. Surgen centros de estudio y programas formativos de business ethics; se difunde en el mundo desarrollado el sistema de certificaciones éticas, siguiendo la línea del movimiento de ideas nacido en torno a la responsabilidad social de la empresa». Con esto puede ser que se quiera justificar que esta economía puede llegar a tener la certificación ética de algún sistema de garantía de calidad al uso, pero nunca podrá tener un certificado de calidad evangélica. Un mínimo análisis desde los textos clave de los evangelios desmonta cualquier posibilidad de legitimación moral de un modelo económico que tiene en el enriquecimiento el motor esencial. Desde el momento en que se reconoce que existe un legítimo lucro, como hace en el número 38, se da carta de ciudadanía evangélica a lo que en términos humanos no es sino robo sistemático a los demás. Pensemos un momento en el fin que tiene la producción de algo, siempre es un fin social, puesto que nada se produce en sí mismo si no es para satisfacer una necesidad social. En el momento en que lo hago para obtener un lucro, es decir, un plus sobre lo que yo mismo necesito para existir, estoy robando a otros de forma directa, yo me lo apropio, o de forma indirecta: a aquellos que vivirán en el futuro y no podrán disponer de lo que yo hoy me he apropiado. El

Este análisis del capitalismo financiero como un sistema de aves rapaces a la espera de sus víctimas ha sido realizado por los grandes pensadores de la economía americana, desde los dos premios Nobel, Krugman y Stiglitz, hasta críticos del sistema como Bello. 
lucro es un robo, se mire como se mire. Ahora bien, quizá sea más grave que se considere que el orden económico, más allá del lucro en sí, presupone el intercambio de cosas equivalentes:

En este caso, caridad en la verdad significa la necesidad de dar forma y organización a las iniciativas económicas que, sin renunciar al beneficio, quieren ir más allá de la lógica del intercambio de cosas equivalentes y del lucro como fin en sí mismo (38).

La economía capitalista no se basa en el intercambio de cosas equivalentes, si alguien intercambia cosas equivalentes no obtiene lucro, éste se consigue mediante el cambio de cosas desiguales, por ejemplo, ocho horas de trabajo a cambio del equivalente de cuatro. Así sí puede haber beneficio y lucro, es decir, plusvalor. Cuando la empresa paga el valor de la mitad del trabajo realizado, la empresa puede obtener un lucro enorme. Es entonces cuando está en disposición de ir al mercado e intercambiar cosas equivalentes. La existencia de las mismas empresas, de la economía capitalista y del mercado libre, se asienta sobre la base de la explotación del ser humano al que se expropia el valor de su trabajo, valor que es el único que está en juego en la economía. Nada hay en el intercambio económico que no sea creado por el trabajo humano, de ahí que el valor que se apropia la empresa es el trabajo humano cosificado en los productos que se venden. Si vamos más allá, incluso diremos que la empresa obtiene el lucro de la apropiación/expropiación de aquello que es único en el hombre: el espíritu, que es aquello capaz de producir algo nuevo donde no lo había. Vale decir que la empresa gana, obtiene beneficio y se lucra con la apropiación del espíritu humano que es el trabajo y que supone un trasunto del Espíritu Santo.

Presuponer un naturalismo económico, como el que vemos que se defiende, nos aboca a una visión pagana —no, no nos equivocamos- de la sociedad y la historia. Nos explicamos. Si la economía capitalista es natural, puesto que no se pone en duda su existencia, sólo su gestión, el mercado es la institución natural que provee los intercambios económicos y el hombre debe aceptarla como tal. Es más resulta casi evangélica, como viene a referirse en el texto siguiente:

la sociedad no debe protegerse del mercado, pensando que su desarrollo comporta ipso facto la muerte de las relaciones auténticamente humanas. Es verdad que el mercado puede orientarse en sentido negativo, pero no por su propia naturaleza, sino por una cierta ideología que lo guía en este sentido. No se debe olvidar que el mercado no existe en su estado puro, se adapta a las configuraciones culturales que lo concretan y condicionan. En 
efecto, la economía y las finanzas, al ser instrumentos, pueden ser mal utilizados cuando quien los gestiona tiene sólo referencias egoístas. De esta forma, se puede llegar a transformar medios de por sí buenos en perniciosos. Lo que produce estas consecuencias es la razón oscurecida del hombre, no el medio en cuanto tal. Por eso, no se deben hacer reproches al medio o instrumento sino al hombre, a su conciencia moral y a su responsabilidad personal y social (36).

Estamos ante un texto netamente ideológico y ante tal sólo cabe más ideología. Está por ver que el mercado sea una institución neutra que se adapta a las aplicaciones que los hombres hacen de él. El medio natural de intercambio no es el mercado sino otro que los antropólogos aducen como más primitivo, por ejemplo el potlatch de los indios americanos. El modelo de intercambio más primitivo y humano es el que presupone el don, como Mauss ha estudiado ${ }^{8}$. El don es un intercambio recíproco en el que no existe un valor objetivo de los productos o servicios que se intercambian, sino que cuenta el valor de la persona y del gesto. El mercado nace cuando la economía se vuelve sedentaria y es necesario atribuir valores sociales objetivos que permitan intercambiar sin perder valor total. El mercado, por ello, estuvo siempre muy limitado y delimitado, incluso mediante un sinfín de tabúes sociales que estipulaban el lugar preciso para el mercado, el tiempo del mismo, los productos a intercambiar y los precios de los mismos. El mercado ha sido siempre considerado como peligroso de facto por todas las culturas neolíticas que lo han utilizado, no es por tanto ni natural ni neutro. Es más, el medio verdaderamente humano, y por extensión cristiano, para relacionarse los seres humanos es la comunidad, la común unidad de los hombres, la comunión de los seres humanos, en el fondo el Espíritu Santo que es el que efectúa la comunión de los hombres y de estos con Dios.

La cita anterior presupone cuestiones muy graves, no sólo que la economía es un instrumento que puede ser mal utilizado, sino que es natural y buena, medios de por sí buenos, dice, sino que además son los más adecuados para el desarrollo de la humanidad y ésta no debe defenderse contra ellos, al contrario, debe adoptarlos como los más idóneos y queridos, si se nos permite insistir, por Dios. El naturalismo económico, por tanto, presupone un sobrenaturalismo político, como decíamos arriba. Para que la humanidad deba aceptar la economía capitalista y el mercado como natural y bueno en sí, debe existir un orden sobrenatural que lo imponga como tal. La supuesta ley natural económica que se esgrime en toda la encíclica, al modo maltusiano o smithiano, sería el

8 M. MAuss: Ensayo sobre el don. Forma y función del intercambio en las sociedades arcaicas. Katz editores, Barcelona 2010. 
trasunto de una ley universal cósmica por la que hay un orden metafísico que presupone y legitima el orden natural, también el económico. El orden sobrenatural predispone que la política, la economía y la sociedad deben regirse por esas supuestas leyes naturales que hacen al hombre lo que es, ahora bien, si esa organización no tiene en cuenta a la Iglesia, pueden pervertirse, como así ha sucedido, y degenerar en un desorden moral que lleva inexorablemente al desorden económico en el que estamos, que no es sino un epifenómeno del desorden moral más profundo en el que la humanidad ha caído por alejarse de los verdaderos valores representados por el cristianismo, como vemos en el texto que sigue:

en el contexto social y cultural actual, en el que está difundida la tendencia a relativizar lo verdadero, vivir la caridad en la verdad lleva a comprender que la adhesión a los valores del cristianismo no es sólo un elemento útil, sino indispensable para la construcción de una buena sociedad y un verdadero desarrollo humano integral (4).

$\mathrm{El}$ adjetivo indispensable, que hemos resaltado, es la clave del texto. $\mathrm{La}$ adhesión a los valores del cristianismo puede ser cualquier cosa, porque eso habría que definirlo, aunque temo que todo el mundo sabe a lo que se refiere, pero que eso sea «indispensable» para una buena sociedad nos dice cómo entiende el autor la organización cósmica que hemos referido antes: hay un orden cósmico que se subdivide en dos principios naturales, uno es el político y el otro el eclesial. Si el primero se encarga de las cuestiones materiales y organizativas, el segundo es el responsable de las espirituales y cosmovisionales. Sin este último el otro está falto de alma y degenera fácilmente en la barbarie, de ahí la necesidad de la adhesión a los valores cristianos.

La razón oscurecida del hombre, como se nos había dicho antes, es la responsable de los males que la economía puede generar, no es el sistema económico en sí. Por ello, esa razón humana, debe estar iluminada por el cristianismo como medio de ser recta y no utilizar la economía como un medio para el enriquecimiento ilícito y la destrucción del orden económico que ha sido querido por Dios, de algún modo, tal y como está. Si la razón humana no es sanada por la fe cristiana, entiende el autor de la encíclica, se pervierte y utiliza el buen orden natural de las cosas en su propio beneficio sin mirar el bien común.

El naturalismo económico presupone el sobrenaturalismo político y este sustenta el ecliocentrismo, es decir, la idea de que la Iglesia católica, con sus valores y sus normas debe ser el centro de un mundo nuevo al que se está avanzado a pasos agigantados, pero que no termina de 
aceptar la guía de la Iglesia. Si el mundo aceptara los valores cristianos, - valores que en todo caso habría que especificar según el Evangelio y no según los que fundan la economía capitalista-, entonces se encaminaría hacia la perfección del amor querida por ese orden cósmico que todo lo rige y funda. Como se expresa en el texto que vemos a continuación, la globalización es querida por Dios y está necesitada de encontrar su verdadero ser en la Iglesia:

el compromiso por el bien común, cuando está inspirado por la caridad, tiene una valencia superior al compromiso meramente secular y político. Como todo compromiso a favor de la justicia, forma parte de ese testimonio de la caridad divina que, actuando en el tiempo, prepara lo eterno. La acción del hombre sobre la tierra, cuando está inspirada y sustentada por la caridad, contribuye a la edificación de esa ciudad de Dios universal hacia la cual avanza la historia de la familia humana. En una sociedad en vías de globalización, el bien común y el esfuerzo por él, han de abarcar necesariamente a toda la familia humana, es decir, a la comunidad de los pueblos y naciones, dando así forma de unidad y de paz a la ciudad del hombre, y haciéndola en cierta medida una anticipación que prefigura la ciudad de Dios sin barreras (7).

Este texto, netamente hegeliano, identifica el proceso de la globalización capitalista como el avance de la familia humana hacia la ciudad de Dios universal, ¿esa ciudad santa donde Dios será todo en todas las cosas? No sabemos si esto puede ser así posible, pues mala familia es esta donde cuatro quintos necesitan lo que al resto le sobra, donde un quinto muere de hambre mientras otro tanto desperdicia lo que haría feliz a la humanidad. No sé cómo se puede afirmar que este mundo es semejante al Reino de Dios. Nuestro reino no es de este mundo precisamente, sino que es este mismo mundo transformado en justicia, amor y solidaridad, cosa imposible tal y como está el orden mundial, la economía capitalista, el imperio global.

A lo largo de la encíclica se respira el aire que Agustín mismo respiraba al final del Imperio Romano. Quizás sea esta la causa de recurrir a aquel pensamiento. Nos encontramos en los finales del Imperio Global Postmoderno, como lo hemos definido en otro lugar ${ }^{9}, \mathrm{y}$ estos finales son semejantes en muchos aspectos a aquellos. Cuando el Imperio Romano caía dejaba una decadencia moral que afectaba a los otros órdenes de la vida y Agustín se preguntó si aquello era voluntad de Dios. Civitate Dei es la respuesta de Agustín a los interrogantes de los

B. PÉREZ ANDREO: "Alternativa cristiana a la globalización postmoderna" Carthaginensia 23 (2007) 1-44. 
tiempos. Dios ha querido la caída del Imperio Romano cristiano como camino para la construcción de un mundo cristiano más amplio. De la misma manera hoy, nos propone la encíclica, Dios quiere la quiebra del mundo global como medio para alcanzar una familia cristiana universal, una nueva Ciudad de Dios donde el cristianismo juega el papel de garante de la moral y la ley natural. Sin el cristianismo, las instituciones humanas se vuelven una mera lucha del hombre por obtener sus propios beneficios a costa de cualquier cosa, de ahí la crisis financiera, epifenómeno al fin de la aguda crisis moral producida por el abandono de los valores cristianos.

Esta ha sido, grosso modo, la exposición de la perspectiva de la encíclica, perspectiva que creemos no acertada en el análisis de la realidad y que da un giro en cuanto exposición de la doctrina de la Iglesia sobre la cuestión social en el siglo XXI. En el siguiente epígrafe haremos una breve lectura de lo que la encíclica ha ocluido como desarrollo del pensamiento anterior de de los pontífices precedentes sobre la configuración de una sociedad mundial basada en el amor y la justicia.

\section{La (excluida) civilización del amor}

El concepto de Civilización del amor como forma de integrar un nuevo modo de relaciones humanas que pueda responder a un mundo cada vez más unido pero carente de los elementos que pueden hacer de él un verdadero mundo humano, fue acuñado por Pablo $\mathrm{VI}^{10} \mathrm{y}$ utilizado por este en varias ocasiones, sin llegar nunca a precisar su sentido, pero con una clara intencionalidad de ser un modelo que nuclee el pensamiento cristiano en un mundo en vías de globalizarse. Se trataba de plantear una alternativa ante la injusticia generalizada. En 1975 el mundo se veía ya con la necesidad de encontrar un camino común donde reine el amor y la justicia. Pero en 1995, con la globalización capitalista galopante, era imprescindible sentar otras bases, como Juan Pablo II propuso en la Asamblea de Naciones Unidas:

la respuesta al miedo que ofusca la existencia humana al final del siglo es el esfuerzo común por construir la civilización del amor, fundada en los valores universales de la paz, de la solidaridad, de la justicia y de la libertad. Y el 'alma' de la civilización del amor es la cultura de la libertad: la libertad

10 PABLO VI: Homilía del solemne rito de clausura del año santo, 25 de Diciembre de 1975. 
de los individuos y de las naciones, vivida en una solidaridad y responsabilidad oblativas ${ }^{11}$.

Esta cita nos indica que una civilización universal no puede tener otro fundamento que valores universales aceptados por todos: la paz, la solidaridad, la justicia y la libertad, siendo esta última el alma de una tal civilización. Compárese ahora con las dos únicas citas que la encíclica reserva para esta nueva vía para el mundo globalizado:

Sus enseñanzas sociales [se refiere a Pablo VI] fueron de gran relevancia: reafirmó la importancia imprescindible del Evangelio para la construcción de la sociedad según libertad y justicia, en la perspectiva ideal e histórica de una civilización animada por el amor (13).

Se trata de ensanchar la razón [habla ahora de Juan Pablo II] y hacerla capaz de conocer y orientar estas nuevas e imponentes dinámicas, animándolas en la perspectiva de esa 'civilización del amor', de la cual Dios ha puesto la semilla en cada pueblo y en cada cultura (33).

Vemos que en la encíclica la perspectiva es meramente ideal y dicha civilización del amor no tiene una virtualidad mayor que ser un referente externo, casi un ideal utópico sin ningún tipo de operatividad real. Según las palabras de la actual encíclica, la civilización del amor es una mera idealidad, lo que sí que habría que construir es una realidad netamente humana basada en los valores cristianos. Si Juan Pablo II proponía una civilización construida sobre valores universales, Benedicto XVI propone una nueva Ciudad de Dios Universal asentada en los valores cristianos:

En el contexto social y cultural actual, en el que está difundida la tendencia a relativizar lo verdadero, vivir la caridad en la verdad lleva a comprender que la adhesión a los valores del cristianismo no es sólo un elemento útil, sino indispensable para la construcción de una buena sociedad y un verdadero desarrollo humano integral (4).

Como se puede comprobar, el giro es neto en la consideración de la sociedad, son los valores cristianos los que resultan indispensables para la construcción de una buena sociedad. Estamos lejos de la perspectiva nacida en el Concilio Vaticano II y continuada hasta Juan Pablo II, que considera lo verdaderamente humano como netamente cristiano y no al

11 JuAn PABlo II: Discurso a la quincuagésima asamblea general de las Naciones Unidas, 5 de Octubre de 1995, 18. 
contrario. Aquello supuso la muerte del agustinismo milenario y el nacimiento de un diálogo fructífero entre el mundo y la Iglesia. De esa perspectiva surge la conceptualización de la civilización del amor como propuesta utópica pero operativa, que opone a este mundo de injusticia, identificado con el capitalismo, un mundo de justicia, amor y misericordia construido sobre valores universales.

Las consecuencias del neoagustinismo son de profundo calado en la percepción de la realidad. En la estela del movimiento neocon estadounidense, se identifica al capitalismo como el modelo económico, social y político natural, pero se hace evidente la necesidad de reconducirlo ante las graves consecuencias que se ven en el mundo. Esa reconducción supone tanto la legitimación del capitalismo como sistema natural, como la propuesta del cristianismo como arreglo de todos los males del mismo. Creo que una explicación de lo que está sucediendo en Haití nos puede hacer comprender los límites de esta visión forcluida de la realidad y la necesidad de devolver la doctrina de la Iglesia sobre lo social al camino de la crítica del capitalismo y a la construcción de una alternativa a la que dos pontífices han denominado Civilización del amor.

Sírvanos como ejemplificación del capitalismo lo que hemos podido contemplar en Haití. En las últimas semanas hemos podido asistir a la peor desgracia acontecida en América en los últimos decenios. El terremoto que ha sacudido Haití no sólo ha supuesto la muerte de más de doscientos mil seres humanos y la desgracia brutal para los que han quedado vivos. También ha supuesto la clarificación del modus operandi del capitalismo, tanto en la creación de la desgracia, como en el aprovechamiento de la misma para seguir generando beneficios, como así lo ha reconocido Clinton en sus manifestaciones post terremoto: «el terremoto es una oportunidad de negocio».

La verdadera tragedia de Haití no ha sido el terremoto sino la imposición de las instituciones financieras capitalistas internacionales como el Fondo Monetario Internacional, el Banco Mundial y la Organización Mundial de Comercio. Hasta el año 1994 Haití era capaz de alimentar a su población con la producción propia, especialmente de arroz. Pero desde esa fecha, los organismos financieros obligaron a Haití, como a tantos países en vías de desarrollo, a aplicar las políticas de liberalización del comercio mundial. Esta liberalización obligó a reducir los aranceles que protegían a los productos propios frente a los ajenos, de modo que el arroz estadounidense pudo entrar libremente en Haití. La trampa residía y reside en que, mientras estos organismos exigen la apertura de mercados a los países empobrecidos, permite que los enriquecidos mantengan las subvenciones a sus productos. Esto sucede con el arroz de Estados Unidos, es más barato por estar subvencionado 
en un claro caso de dumping económico. En pocos años la agricultura haitiana se hundió y expulsó al diez por ciento de la población hacia los guetos de Puerto Príncipe, pasando así a engrosar las filas de la miseria, la delincuencia o la prostitución ${ }^{12}$.

Esta liberalización de los mercados provocó las ingentes cantidades de hambrientos que llevaban a la muerte a miles de niños haitianos subalimentados de manera crónica. 30.000 muertos al año en diez años supone el doble de los muertos del terremoto, y si no cambia nada, seguirán muriendo porque Haití no tiene la capacidad para producir lo que necesita, entre otras cosas porque los haitianos, en un acto de desesperación suicida, han talado todos sus bosques para conseguir algo de ingresos. Las tierras desnudas pierden su capa fértil tras las lluvias torrenciales; los ríos no fluyen con regularidad; los ricos valles dejan de producir de forma permanente. Todo esto ha sido consecuencia de las políticas de liberalización del Mercado, del dios Molok que exige sacrificios humanos. Ese Mercado capitalista es el responsable de los miles de muertos en Haití antes del terremoto y de las grandes sumas que ingresan las maquiladoras instaladas al calor del dinero que el FMI presta a Haití, dinero que debe el pueblo y del que se benefician las multinacionales. Allí han encontrado éstas su propio paraíso: masas de empobrecidos dispuestos a trabajar por lo que sea las horas que se les obligue. Ese paraíso capitalista es el infierno en la tierra y no podemos ni legitimarlo, ni sustentarlo, ni reconocerlo. Hay que destruirlo como medio para ser realmente seguidores de Jesús de Nazaret, como forma de ser cristianos.

El capitalismo es el gran enemigo de la humanidad, como vemos en el caso de Haití, de existir un estado normal que vele por el bien común y no un gobierno impuesto por la codicia del sistema que sólo mira por el beneficio propio y de las multinacionales, las consecuencias del terremoto habrían sido netamente inferiores. No podemos abandonar la línea abierta por Pablo VI de la necesidad de avanzar a una civilización del amor en la que los pueblos se relacionen para la consecución de la justicia y bajo la égida del bien común. Para conseguir esto debemos criticar primero y destruir después el modelo capitalista de desarrollo que supone el sufrimiento de cuatro quintas partes de la humanidad.

La propuesta cristiana alternativa debe encaminarse desde la propuesta de una civilización del amor y también de la pobreza, como ya

12 Cfr. J. B. Bonny: "Liberalización comercial y producción de arroz en Haití", Observatorio de la Economía Latinoamericana 87 (2007), http:/ /www.eumed.net/cursecon/ ecolat/ht/bjb-arroz.htm. 
han tematizado Ellacuría y Sobrino ${ }^{13}$. En las propias palabras de Jon Sobrino: «la civilización de la pobreza supone el des-quiciamiento del mundo actual, es decir, una alteridad radical». Porque la civilización de la riqueza ha fracasado. La promesa de un mundo donde los hombres puedan vivir el paraíso en la tierra se ha tornado una terrible amenaza de autodestrucción. El sueño de la razón sigue creando monstruos y la inmensa mayoría de los hijos de Dios padecen indecibles penurias, mientras una mínima parte de la humanidad se atraganta con su hartazgo de consumo. La civilización de la pobreza «rechaza la acumulación de capital como motor de la historia y la posesión-disfrute de la riqueza como principio de humanización, y hace de la satisfacción universal de las necesidades básicas el principio del desarrollo y del crecimiento de la solidaridad compartida el fundamento de la humanización» ${ }^{14}$.

La civilización del amor y la pobreza emanan directamente del evangelio de Jesús de Nazaret y es la única alternativa viable a un mundo donde la riqueza se genera a partir de la ingente cantidad de pobreza obscena que somete a las masas de hijos de Dios sufrientes. Por mucho que queramos, el camello no entrará por el ojo de la aguja ni el mundo rico en el Reino de Dios.

En estas circunstancias puede que el Aquinate vuelva a tener razón. Cuando cuatro quintas partes de la humanidad sufren graves carencias de los recursos básicos para su subsistencia, mientras el quinto restante disfruta de enormes cantidades de bienes superfluos, puede que sea necesario aplicar aquellas sabias palabras del santo doctor:

el usar de la cosa ajena ocultamente sustraída en caso de extrema necesidad no tiene razón de hurto propiamente hablando, puesto que por tal necesidad se hace suyo lo que uno sustrae para sustentar su propia vida. $[\ldots]$, en el caso de una necesidad semejante también puede uno tomar clandestinamente la cosa ajena para socorrer así al prójimo indigente. [...] si los príncipes exigen a los súbditos lo que conforme a justicia se les debe para conservar el bien común, no cometen rapiña, aunque empleen la violencia ${ }^{15}$.

Dicho con otras palabras: ante la situación criminal de la muerte inocente de millones de seres humanos y ante la más que probable destrucción del hábitat planetario, sería legítimo que los pobres tomaran lo que es suyo por derecho, o bien otros lo tomen para ellos, o bien una autoridad legitimada por la justicia impida a unos cuantos acumular el

13 J. SOBRINO: "Revertir la historia", Concilium 308 (2004) 146.

14 Ibíd.

15 Summa Theologica II, II, q 66. a. 7-8. 
sustento de muchos millones, impidiendo a la vez la destrucción de nuestra casa común.

\section{Epílogo}

Como decíamos en el inicio de esta lectura de Caritas in veritate, la encíclica ha llevado a cabo una forclusión del término capitalismo, no se trata de que se corrija una percepción inapropiada de la sociedad como es el capitalismo, sino que el término ha desaparecido del discurso, pero la realidad sigue estando ahí, tozuda como siempre, para imponerse y cobrarse sus reales. No por no citarlo el capitalismo dejará de ser el sistema económico, social y político que gobierna y rige los destinos de, ahora sí, toda la humanidad. No basta con culpar a la razón oscurecida del hombre, ni a la pérdida de los fundamentos éticos de los inversores, ni a la confusión entre fines y medios, ni a la perversión de la moral moderna. No, no se trata de malas aplicaciones de correctas recetas económicas, se trata de que el capitalismo es en sí mismo un sistema perverso de organización social, no es el orden natural de las cosas, ni mucho menos querido por Dios. El capitalismo es la explanación social del famoso seréis como dioses, tras estas palabras la humanidad quedó prendada en su corazón y en su acción, convirtiendo todo lo posible en beneficio y lucros, sin atender a las consecuencias naturales y humanas de tal aplicación. Como dijera Kafka, el capitalismo es un estado del mundo y un estado del alma. El ser humano, desde el advenimiento de la modernidad capitalista, y más específicamente desde la configuración del orden monopolístico capitalista, cuyo fruto último es la globalización, ha perdido su capacidad para ser lo que varios millones de años de evolución consiguieron: un ser humano concreto. Desde el advenimiento de la postmodernidad globalizada capitalista, la humanidad ha entrado en un periodo de pérdida de su ser y de destrucción del medio de vida y de la humanidad misma de los hombres.

El actual estado de crisis sistémica capitalista, como lo explican los analistas serios, no así los estipendiados por el modelo económico capitalista, no se ha debido a una mala aplicación del modelo, ni a la razón oscurecida del hombre, ni siquiera a la sola avaricia de unos cuantos; la crisis sistémica depende de la lógica propia del sistema capitalista: se trata de un sistema económico de destrucción generalizada, no de intercambio generalizado, es un sistema que necesita convertirlo todo en capital, es decir, necesita destruirlo todo al transformarlo en beneficio objetivo. El capitalismo es el mayor crimen que se ha cometido 
contra la humanidad y no podemos contemporizar con este mal que está destruyendo a la humanidad.

Esta encíclica es un acto fallido, y será necesario reconducir otra vez la doctrina social hacia la línea que desde el Concilio Vaticano II nos llevaba, tortuosamente, hasta Centessimus annus. A menos que aceptemos la kehre que esta encíclica supone respecto a la doctrina precedente. El giro ha sido brutal, pues de criticar el capitalismo hemos pasado, no sólo a aceptarlo, sino a considerarlo como natural al hombre y al mundo, mediante el proceso de no cuestionarlo, de ni siquiera nombrarlo. Esta forclusión del término, por la cual ya no se habla de ello porque se presupone como lo lícito, es un gran motivo de riesgo para el cristianismo en los tiempos que corren. De la misma manera que el agustinismo modeló el cristianismo durante el milenio que siguió a su formulación, este neoagustinismo puede suponer la desaparición del último reducto de lo que hemos entendido en los años posteriores al Concilio como catolicismo, haciéndose necesaria una reformulación completa del mismo. Si no ayudamos a reconducir esta kehre de la doctrina social, podemos vernos en la necesidad de plantear el grave problema del ser eclesial al nivel más alto y más grave posible. Las consecuencias pueden ser importantes, aunque estamos convencidos de que las puertas del abismo no prevalecerán.

Sumario: Introito; 1. Hacia la civilización del amor; 2. La (excluida) civilización del amor; Epílogo. 